\title{
THE USE OF HEDGING DEVICES IN APPLIED LINGUISTICS ACADEMIC DISCOURSE: THE CASE OF READING IN A FOREIGN LANGUAGE AND ENGLISH LANGUAGE TEACHING RESEARCH ARTICLES
}

\author{
Nguyen Tuan Anh* \\ Faculty of English Language Teacher Education, VNU University of Languages \\ and International Studies, Pham Van Dong, Cau Giay, Hanoi, Vietnam
}

Received 24 August 2018

Revised 27 September 2018; Accepted 28 September 2018

\begin{abstract}
Hedging enables academic writers to mitigate claims and minimize the impositions that may be found in such claims (Hyland, 1996). Although the literature has had vast research on hedging in research articles, not much has been known about the difference or similarity among journals in one field in the use of hedging devices. Using the document analysis method, the present study aims to make a comparative analysis of hedging in two linguistics research journals, namely Reading in a Foreign Language (RFL) and English Language Teaching (ELT), in order to investigate what hedging forms and functions are most frequently used in RFL and ELT, and how hedging forms and functions are distributed in the Introduction, Results, Discussions and Conclusions sections in the two journals. Based on the data analyzed, it was found that RFL and ELT research article writers tend to have the same preference for the use of different hedging forms for different equivalent purposes and functions. This similar hedging pattern is believed to be of value to those who are trained as academic writers in the field of linguistics.
\end{abstract}

Keywords: hedging, hedging devices, rhetorical sections, academic writing

\section{Introduction}

Recent years have witnessed an extensive number of investigations into the hedging phenomenon and the use of hedging devices in academic discourse. According to Hyland (1996), hedging devices have proved to be an indispensable part in academic writing by constituting "an essential element of argumentation in presenting new claims for ratification" (p. 452). Generally, "hedging is

*Tel.: 84-948631359

Email: tuan34anh2@gmail.com the expression of tentativeness and possibility and it is central to academic writing where the need to present unproven propositions with caution and precision is essential" (Hyland, 1996, p. 433).

Hedges are linguistically defined as rhetorical devices which are mostly presented by verbal and adverbial expressions (e.g., can, perhaps, suggest, possibly) concerning degrees of probability and serving to bridge between the propositional information in the text and the writer's factual interpretation (Salager-Meyer, 1997). The right strength 
and reasonableness conveyed in a claim can be considered the most significant motivation for the use of hedging devices in academic discourse. "The art of the matter" - hedging (Swales \& Feak, 1994, p. 77) - enables academic writers to avoid claiming "more than is reasonable or defensible" (Swales \& Feak, 1994, p. 86) and to mitigate claims as well as minimize the impositions that may be found in such claims (Hyland, 1996, p. 434). In other words, hedging enables academic writers to show their certainty or uncertainty towards their statements, to show the amount of confidence they put on their claim, and to start a dialogue with their readers by leaving some room for the readers to judge the truth value of the assertion.

This phenomenon was first introduced by Lakoff (1972) in a paper entitled "Hedges: A study in meaning criteria and the logic of fuzzy concepts" (Hua, 2006). Since then, the term "hedge or hedging" has been developed in the Politeness theory (e.g. Brown and Levinson, 1987; Coates, 1987), "associated with conveying purposive vagueness” (e.g. Dubois, 1987; Channell, 1994), and treated as a form of metadiscourse (e.g. Crismore, Markkaned, and Steffesen, 1993) (Hyland, 1996, p. 433).

In the field of academic writing, studies on the use of hedging devices have been expanded to a wide range of research fields and disciplines. Hua (2006) compares the use of scientific English hedging by Chinese writers and native English writers, in an attempt to investigate whether Chinese writers of English research articles "meet international standard in their use of hedging in their RAs" (p. 58) through an analysis of ten published research articles in English (five by English writers and five by Chinese writers) in the field of material science. By using the hedging categories (approximators
- related to truth-conditional semantics, and shields - related to non-truth conditional pragmatics) proposed by Zhang (1998), Hua finds that although there is some similarity in the ranking of the frequencies of hedging forms, "the difference between the two groups are even more revealing” (p. 60). Chinese writers do not hedge their RAs as frequently as English writers on the whole and prefer approximators over shields, that is, they "tend to be more direct and authoritative in tone and to make strong modals than English writers" (p. 61). However, what seems to be missing in Hua (2006) is a wider categorization of English hedging forms and deeper discussions of writer cultural standing as well as each hedging category's functions which may have a critical saying in the differences between two groups of writers.

Also recognizing the effects of culture and linguistic variations on hedging use, Vassileva (2001) focuses on the differences between hedges and boosters - boosters "termed as 'solidarity' (the case when the author claims shared knowledge with the audience) and 'belief' (when the author states unequivocally that he/she is absolutely convinced of what he/she is saying)" (p. 86). By analyzing 180 pages of linguistics research articles (60 for each of English, Bulgarian, and Bulgarian English), Vassileva finds that all of the writers in the three languages employ hedging and that "they use approximately the same linguistic means of expressing boosting and hedging" (p. 98). Differences are also observed with a higher degree of commitment in Bulgarian and Bulgarian English than English as "English writers are much more tentative in putting forward claims and in rejecting or confirming others' opinion, thus avoiding the so-called 'Face-Threatening Acts'” (p. 87). The "self-assertion strategy" is considered to be a possible explanation to the more frequent 
use of boosters - showing more commitment - by Bulgarian and Bulgarian English. Based on these findings, Vassileva suggests that Bulgarian writers should "master the English standards of academic writing in order to be able to incorporate themselves fully in the English-speaking academic discourse community" and "native speakers of English as members of the constantly expanding academic discourse community should be made aware of the existence of other, different cultures, and rhetorics, and learn to be tolerant of their specificities" (p. 100).

Mojica (2005), motivated by Vassileva (2001), has also centered on the need of distinguishing between hedges and boosters. In brief, while hedging devices are almost likely to be used to "help negotiate the perspective from which the conclusion can be accepted", boosting devices may be employed as "way of impressing with his/ her knowledge of the topic being discussed" in cases of such phrases as "I think / It is my belief that / I believe..." to "show the authors' commitment to their propositions" (Mojica, 2005 , p. 516). From this distinction, Mojica, after an analysis of five English engineering (71 pages) and four English linguistics (68 pages) research articles written by Filipino professors at De La Salle University-Manila, has found that although there seems to be little difference in the distributions of hedges among two groups, the linguistics group tends to use more varied types of hedging than the engineering one; linguistics and engineering articles show the writers' tendency to hedge most in the Introduction section, followed by the Discussion, and least in the concluding part; and the linguistics group tend to use more hedges and the engineering group tends to use more boosters (p. 518-522).

The concern that arises from the two extensive investigations of Vassileva (2001) and Mojica (2005) appears to be that it is, probably, their distinction between hedges and boosters that differentiates themselves from Hyland (1996) and Swales \& Feak (1994) in terms of hedging definition. Words like "definitely, certainly" are best examples of boosting, but "I/We believe, It is a wellknown fact that" may not be. On the one hand, Vassileva (2001, p. 84) agrees with Hyland's (1996) definition of hedging as a device which "helps negotiate the perspective from which conclusions can be accepted"; on the other hand, Vassileva treats personal attribution (e.g. I believe) not as a hedging device but a booster while, according to Hyland (1996), such a device could also be considered as hedging, and, in addition to weakening criticism, may also be used to soften claims in the way that "by specifying a personal source, the writer leaves the claim open to the reader's judgement" (p. 448). Swales \& Feak (1994) also consider the phrase "It is a well-known fact that" as a way of expressing writer distance from a claim by introducing common knowledge. Therefore, Vassileva (2001) and Mojica (2005) just take into account the definition of hedging as "content-oriented". It should also be notable that, as Vassileva (2001) admits, "the taxonomy of hedges and boosters adopted in this research is a somewhat loose one" (p. 86 ), that is, one form may function as both a hedge or a booster. Together with different cultures in academic writing (in this case three language variations), a so-called booster may not necessarily be a booster itself in the view of a writer.

Varttala's (1999) study on the use of hedging in medicine research articles has been one of important ones in the field of ESP (English for Specific Purposes). A collection of 15 medical articles from Scientific American (SA) and 15 specialist research articles from The New England Journal of Medicine 
(NEJM) were analyzed based on "a selection of lexical items that the readers of scientific texts are most likely to interpret as hedges" (p. 182), namely modal auxiliaries (e.g. may), main verbs (argue, believe), adverbs (possibly, perhaps), adjectives (potential, probable) and nouns (hypothesis, idea, notion). Although it would have been better if she had extended her taxonomy of hedging, the focus on five lexical classes might apparently help her construct a more insightful understanding as "it can be claimed that lexical items are among the phenomena that the readers of scientific texts most readily associate with hedging" and "the choice falls predominantly upon lexical hedging elements" (p. 183). According to the analysis, modal auxiliaries and lexical verbs are the most frequently used, followed by modal adjectives, adverbs, and nouns, and the most devices are found to occur in the Discussion and Introduction sections of the research articles. Varttala argues that such findings not only support previous studies but also provide evidence against the assumption that "hedges are not used or needed in the rhetoric of scientific popularization", because "hedges, expressions linked to conceptual fuzziness, can be used very effectively in peer communication between medical specialists as a textual tool for precision and, simultaneously, as an interpersonal negative politeness strategy" (p. 190). Perhaps, it is for this attempt that Varttala's (1999) study distinguishes itself from early studies on hedging in ESP, despite a limited taxonomy of hedging forms studied.

Generally, although the literature has had vast research on hedging in research articles, not much has been known about whether different journals in one field differ from each other in the use of hedging devices. For this reason, the present study aims to make a comparative analysis of hedging in two applied linguistics research journals, namely Reading in a Foreign Language (RFL) and English Language Teaching (ELT), in order to answer the following research questions:

\section{What are the similarities and differences} in hedging forms and functions used in RFL and ELT?

2. What are the similarities and differences in hedging forms and functions distributed in the Introduction, Results, Discussions and Conclusions sections in RFL and ELT?

The Method section is not included in the study because, as Salager-Meyer (1997) suggests, "the frequency of occurrence and types of hedges are not evenly distributed throughout different sections of academic papers", and, especially, "hedges appear least in the almost purely factual (i.e. unhedged) Methods section, the least discursive and commentative section of academic papers where confirmatory statements are the rule".

\section{Framework of study}

In the Politeness model proposed by Brown \& Levinson (1987), hedging is considered a strategy through which negative and positive politeness in natural conversation is realized. Brown \& Levinson define a "hedge" as "a particle, word, or phrase that modifies the degree of membership of a predicate or noun phrase in a set; it says of that membership that it is partial, or true only in certain respects, or that it is more true and complete than perhaps might be expected" (p. 145). Researchers have argued that the politeness view has not been an adequate explanation for the use of hedging in academic discourse and have called for a more insightful means of analyzing the interpersonal use of hedges in academic settings (Hyland, 1996).

The functional model of hedging proposed by Hyland (1996) has been thought to be the result of controversy on the Politeness 
model and of the observation that "hedging in scientific research writing represents a littlestudied area of pragmatic competence and we still know little about how it functions and is typically realized in specific academic domains" (p. 434). One of the most important points of Hyland's study is his recognition of "the fact that hedging represents a writer's attitude within a particular context" and "a need for an explanatory framework which accounts for its pervasiveness in academic discourse by situating hedging in its sociopragmatic contexts" (p. 434). Hyland argues that although the assumption that "hedges are part of a wider system of politeness" is "clearly suggestive and central to any discussion of hedging", treating hedging as politeness puts more stress on the instrumental than on the normative, "thereby underplaying the importance of authority and conformity in academic discourse community, and at the same time neglects the multi-functional character of hedges in gaining acceptance for claims."

In academic discourse, Hyland supposes that "no matter how clearly, convincingly, and appropriately reader-centred material may be expressed", "readers can always refute a claim" (p. 436), that is, readers may be persuaded to judge a claim acceptable or may decide to reject it. In this way, by signalling the writer's anticipation of the opposition to a proposition, hedging "anticipates a need to justify claims because the writer is dependent on their ratification by the reader". Based on this opposition, Hyland proposes a model of hedging in the context of academic discourse as shown in Figure 1.

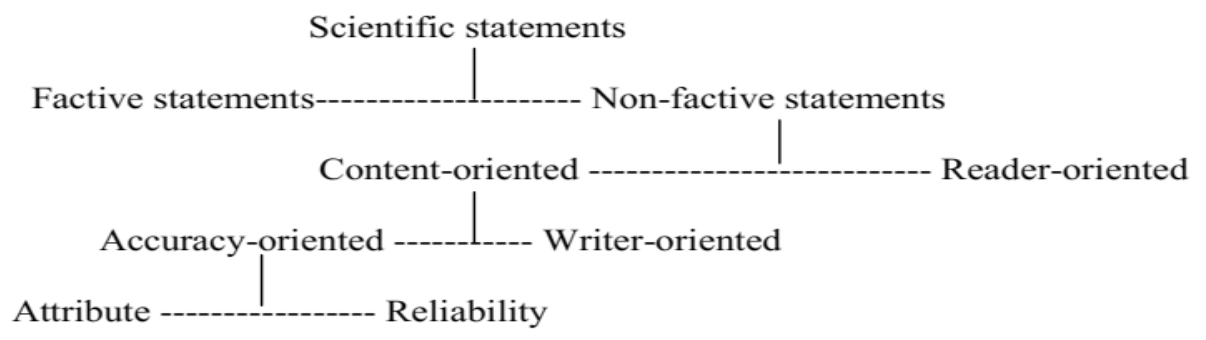

Figure 1. Categorization of Scientific Hedges (Hyland, 1996, p. 438)

Salager-Meyer (1997) may have made a rather more concrete classification of hedging devices in scientific English, including seven categories: (1) Modal auxiliary verbs; (2) Modal lexical verbs; (3) Adjectival, nominal and adverbial modal phrases; (4) Approximators of degree, quantity, frequency and time (5) Introductory phrases; (6) If clauses; and (7) Compound hedges.

Swales and Feak (1994) discuss ways of qualifying or moderating the strength of a claim by being "confidently uncertain" in making claims (Skelton, 1988, in Swales \& Feak, 1994, p. 86). Accordingly, useful hedging devices include (1) Probability expressions (e.g. may, likely, possibility), (2) Distance expressions (e.g. seem, appear, based on, according to, in the view of, on the limited data available), (3) Generalization qualifications (e.g. tend, most, many people think that, a majority of, with the exception of, apart from), (4) Weaker verbs (e.g. suggest, contribute to, indicate, question, assume), and (5) Combined qualifications (e.g. may reduce certain types of injury in some circumstances). It may be argued that although Swales and 
Feak's classification has touched upon the fundamental characteristics and components of hedging devices in academic papers, it would clearly appear to be not so adequate as Hyland's (1996) and Salger-Meyer's (1997) frameworks in terms of both hedging forms and functions.

For the purpose of convenience in categorizing hedging forms and functions, this study's framework is adopted from Hyland (1996), Salager-Meyer (1997), and Swales \& Feak (1994). Of course, there would, perhaps, be no framework that could completely cover such a broad area of hedging, but, at least, such a combination, presumably, might help construct a comprehensive set of both hedging forms and functions.

- Attribute:

Downtoners: in some ways, quite, partially, barely, roughly, essentially, slightly

Approximators: generally, approximately, around, often, somewhat, somehow, usually, significantly, relatively, most, , a majority of, in many cases

Qualification: viewed in this way, from a practical point of view, based on, according to, in the view of, many people think that

- Reliability:

Modal auxiliary verbs: may, might, can, could, would, should

Modal adjectives, nouns, and adverbs: possible, possibility, probably

Content disjuncts: presumably, apparently, virtually, practically

Limited knowledge: It is not known whether, poorly understood

- Writer-oriented:

Impersonal expressions and Compound hedges: be assumed to, It might be speculated, It would indicate, This probably indicates that, It seems reasonable to assume that, It would seem somewhat unlikely that, The present work indicates/demonstrates that

Modal lexical verbs (and some corresponding nouns and adjectives): indicate, assume, predict, propose, appear, seem, imply, suggest, believe, estimate, tend, think, argue, speculate

Impersonal reference to research methods, conditions, and models: under these conditions, the prediction of this model, despite the limitations of this method, on the limited data available

- Reader-oriented:

Personal attribution: I believe, to our knowledge, It is our view that, we feel/believe that

Offering a claim as one possibility among many: one of

Hypothetical conditions: if we assume that, if true, if anything

Rhetorical questions: Why do such temporal changes occur? Could such a putative interaction have a physiological significance?

\section{Methodology}

The study was conducted through a quantitative analysis of five articles from the RFL Journal (53 pages, 12277 words) and five articles from ELT Journal (49 pages, 11835 words), all of which were published during the period from 2000-2010. It should be noted that the number of pages includes all parts of an article while the number of words only includes three sections (Introduction, Results, Discussions and Conclusions) that are investigated in this study. Also, the first and foremost criterion for an article to be chosen for analysis is that there must be a clear-cut boundary among rhetorical sections. Because there are articles in which the Discussions sections are combined with the 
Results, it would be impossible in such cases to determine to which section, Results or Discussions, one hedging form belongs.

The procedure of coding data was conducted in two steps. First, when a hedging form was identified, the sentence or phrase containing that form was then transferred to a collection table. In this way, the context where a hedge occurs is maintained. In the next step, hedges were coded according to the framework of the study for each journal. In this way, the author was able not only to capture the frequency distributions of hedges in general, but also know exactly what particular hedging lexical item is more frequently used.

\section{Results}

\subsection{Distribution of hedging forms}

Table 1 shows the total number of hedging forms which were employed in three RFL and five ELT research articles, and, more specifically, the total number of each form.

Table 1. Frequency of hedging forms in sampled RFL and ELT research articles

\begin{tabular}{|c|c|c|c|c|}
\hline \multirow{2}{*}{ Hedging forms } & \multicolumn{2}{|c|}{ RFL } & \multicolumn{2}{c|}{ ELT } \\
\cline { 2 - 5 } & frequency & $\mathbf{\%}$ & frequency & $\%$ \\
\hline Modal auxiliary verbs & 88 & 33.1 & 116 & 48 \\
\hline Approximators & 43 & 16.2 & 35 & 14.5 \\
\hline Modal lexical verbs (nouns, adjectives) & 45 & 17 & 34 & 14.2 \\
\hline Modal adjectives, adverbs, and nouns & 37 & 14 & 29 & 12 \\
\hline Qualifications & 2 & 0.8 & 9 & 3.7 \\
\hline Downtoners & 12 & 4.5 & 5 & 2.1 \\
\hline Impersonal passive \& compound hedging & 4 & 1.5 & 5 & 2.1 \\
\hline Impersonal reference to method/conditions & 4 & 1.5 & 3 & 1.2 \\
\hline Hypothetical conditions & 18 & 6.8 & 3 & 1.2 \\
\hline Rhetorical questions & 1 & 0.4 & 2 & 0.8 \\
\hline Content disjunct & 1 & 0.4 & 0 & 0 \\
\hline Limited knowledge & 2 & 0.8 & 0 & 0 \\
\hline Possibility among many & 8 & 3 & 0 & 0 \\
\hline Total & 265 & $100 \%$ & 241 & $100 \%$ \\
\hline
\end{tabular}

As can be seen, there appear to be considerable similarities between the two journals in terms of hedging forms employed. First of all, there is only a very slight difference of around 20 forms out of the total between RFL and ELT; in terms of hedges per 1000 words, the results seem to be quite supportive, 21.6 and 20.4 for RFL and ELT respectively. Second, the highest numbers of forms in both groups mainly fall into approximators with $16.2 \%$ (RFL) and $14.5 \%$ (ELT), modal auxiliary verbs (33.1\% and $48 \%$ respectively), modal adjectives, adverbs and nouns (14\% and $12 \%$ respectively) and modal lexical verbs (17\% and $14.2 \%$ respectively). The result would appear to be no surprise because it significantly supports the findings of early studies (Hua, 2006; Mojica, 2005, Vassileva, 2001; Varttala, 1999). The following examples are taken from the sampled articles:

(1) This, plus the visual evidence of the graph in Figure 6, suggests that even at Level 2 of the OBL, it is possible to write simplified prose...

(2) Anxiety in L1 also seems to support this interpretation... 
(3) The majority of the students' writing consisted of sentence fragments...

(4) Age, it would appear, is likely to affect task preferences...

Moreover, the two groups also share the finding that there is a relatively large difference between these forms and the rest. In RFL, for example, qualifications, content disjuncts, limited knowledge, and rhetorical questions cannot exceed $1 \%$ of the total; especially, in ELT, there are even no content disjuncts and limited knowledge found. The use of hypothetical conditions (if) and

Table 2. Calculation of the Spearman Rank-order correlation coefficient

\begin{tabular}{|c|c|c|c|c|c|}
\hline Forms & $\begin{array}{c}\text { Ranking 1 } \\
\text { RFL }\end{array}$ & $\begin{array}{c}\text { Ranking 2 } \\
\text { ELT }\end{array}$ & Difference D & $\mathbf{D}^{2}$ & \\
\hline Modal auxiliary verbs & 1 & 1 & 0 & 0 & \\
\hline Modal lexical verbs (nouns, adjectives) & 2 & 3 & -1 & 1 & \\
\hline Approximators & 3 & 2 & 1 & 1 & \\
\hline Modal adjectives, adverbs, and nouns & 4 & 4 & 0 & 0 & \\
\hline Hypothetical conditions & 5 & 7 & -2 & 4 & \\
\hline Downtoners & 6 & 6 & 0 & 0 & \\
\hline Possibility among many & 7 & 9 & -2 & 4 & \\
\hline Impersonal passive \& compound hedging & 8 & 6 & 2 & 4 & \\
\hline Impersonal reference to method/conditions & 8 & 7 & 1 & 1 & \\
\hline Qualifications & 9 & 5 & 4 & 16 & \\
\hline Limited knowledge & 9 & 9 & 0 & 0 & \\
\hline Content disjunct & 10 & 9 & 1 & 1 & \\
\hline Rhetorical questions & 10 & 8 & 2 & 4 & \\
\hline N=13 & & & Total & 36 & $\mathrm{r}_{\mathrm{s}}=0.90$ \\
\hline
\end{tabular}

The computing procedure provides us with the $r_{s}$ positive value of 0.90 which indicates, according to statistics principles of decision making for Spearman test, that there is a very high positive correlation between the two rankings. This result of the test allows us to confirm that, at least based on the data analyzed, linguistics research article writers in both journals of RFL and ELT tend to prefer certain types of hedging forms. downtoners seems to be not much preferred, around $6 \%$ or lower. These similarities would apparently suggest that there seems to be a tendency in the use of hedging forms in EFL and ELT journals in particular and in applied linguistics journals in general.

In order to seek more evidence for this argument, a statistical tool, Spearman Rankorder Correlation Coefficient $r_{s}$, is used to determine whether or not the correlation between the two journal groups in terms of hedging form ranking is reliable. Table 2 illustrates the procedure:

\subsection{Distribution of hedging functions}

According to Hyland (1996), hedges are often employed to serve four fundamental functions: attribute which refers to how far results approximate to an idealized state, reliability which refers to the writer's assessment of certainty, writer-oriented which refers to the diminishing of the writer's presence in the text, and readeroriented which refers to the writer's invitation towards readers to participate in a dialogue. The following table presents the distribution of the four functions in the two journal groups. 
Table 3. Frequency of hedging functions in sampled RFL and ELT research articles

\begin{tabular}{|c|c|c|c|c|}
\hline \multirow{2}{*}{ Functions } & \multicolumn{2}{|c|}{ RFL } & \multicolumn{2}{c|}{ ELT } \\
\cline { 2 - 5 } & frequency & \% & frequency & $\%$ \\
\hline Attribute & 57 & 21.5 & 49 & 20.3 \\
\hline Reliability & 128 & 48.3 & 145 & 60.2 \\
\hline Writer-oriented & 53 & 20 & 42 & 17.4 \\
\hline Reader-oriented & 27 & 10.2 & 5 & 2.1 \\
\hline Total & 265 & $100 \%$ & 241 & $100 \%$ \\
\hline
\end{tabular}

As shown in Table 3, hedges used to function as reliability appear to occur most frequently in both RFL and ELT, accounting for more or less than $50 \%$ of the total. Interestingly, this hedging function is followed by attribute, writer-oriented, and reader-oriented in both groups. By using the same Spearman Rankorder correlation test, it is found that the $r_{s}$ value reaches 1 , which indicates that the data from eight samples reveal a perfect positive correlation which means that both groups of RFL and ELT writers have a tendency to put more stress on assessing the certainty of the propositional truth and the precision of knowledge claimed. However, it does not necessarily mean that they "devalue" the roles of other functions. One possible explanation may be drawn from Table 4 which reveals the distribution of hedging functions across three sections of research articles.

Table 4. Frequency of hedging functions across rhetorical sections

\begin{tabular}{|c|c|c|c|c|c|c|}
\hline \multirow{2}{*}{ Functions } & \multicolumn{2}{|c|}{ Introduction } & \multicolumn{2}{c|}{ Results } & \multicolumn{2}{c|}{ Discussions and Conclusions } \\
\cline { 2 - 7 } & RFL & ELT & RFL & ELT & RFL & ELT \\
\hline Attribute & 17 & 5 & 18 & 27 & 22 & 17 \\
\hline Reliability & 24 & 27 & 22 & 27 & 82 & 91 \\
\hline Writer-oriented & 4 & 9 & 23 & 8 & 26 & 25 \\
\hline Reader-oriented & 9 & 2 & 0 & 0 & 18 & 3 \\
\hline
\end{tabular}

The first thing that can be inferred from Table 4 is that in both journal groups attribute and reliability turn out to occur with relatively high frequency in all three rhetorical sections while writer-oriented and reader-oriented appear to most frequently in the Discussions and Conclusions. It would be unreasonable for one to argue that the reason for such a distribution is that the Discussions and Conclusions section in an article is usually longer than others, as among eight samples from the two journals there are some in which the Introduction and Results are longer than the Discussions and Conclusions. If so, it could be assumed that the possible explanation lies in the purpose of the writer in each rhetorical section. As Salager-Meyer (1997) suggests, it is in the discursive and speculative Discussions and Conclusions section that "authors put forward controversial ideas or interpretations and hence most feel the need of protecting themselves from 
counter argument or other forms of attack." In other words, it seems that it is in this section that a wider range of hedging forms should be used to serve more self-protection strategies, among which shielding oneself and getting ready to "sit down for professional dialogue" are significantly effective strategies together with attribute and reliability.
4.3. Distribution of hedging forms across rhetorical sections

This part of the study makes an attempt to analyze how hedging devices are distributed across different sections of RFL and ELT research articles and figure out whether there is a significant difference between RFL and ELT in terms of rhetorical distribution.

Table 5. Frequency of hedging forms across rhetorical sections

\begin{tabular}{|c|c|c|c|c|c|c|}
\hline \multirow{2}{*}{ Forms } & \multicolumn{3}{|c|}{ RFL } & \multicolumn{3}{c|}{ ELT } \\
\cline { 2 - 7 } & Introd. & Results & D \& C & Introd. & Results & D \& C \\
\hline Downtoners & 1 & 3 & 8 & 0 & 2 & 3 \\
\hline Approximators & 14 & 15 & 14 & 0 & 24 & 11 \\
\hline Qualifications & 2 & 0 & 0 & 5 & 1 & 3 \\
\hline Modal auxiliary verbs & 17 & 9 & 62 & 23 & 17 & 76 \\
\hline Modal adjectives, adverbs, and nouns & 7 & 11 & 19 & 4 & 10 & 15 \\
\hline Content disjunct & 0 & 1 & 0 & 0 & 0 & 0 \\
\hline Limited knowledge & 0 & 1 & 1 & 0 & 0 & 0 \\
\hline Impersonal passive \& compound hedging & 0 & 1 & 3 & 1 & 0 & 4 \\
\hline Modal lexical verbs (nouns, adjectives) & 4 & 21 & 20 & 8 & 8 & 18 \\
\hline Impersonal reference to method/condition & 0 & 1 & 3 & 0 & 0 & 3 \\
\hline Possibility among many & 4 & 0 & 4 & 0 & 0 & 0 \\
\hline Hypothetical conditions & 4 & 0 & 14 & 1 & 0 & 2 \\
\hline Rhetorical questions & 1 & 0 & 0 & 1 & 0 & 1 \\
\hline Total & 54 & 63 & 148 & 43 & 62 & 136 \\
\hline
\end{tabular}

The results in Table 5 show that in both types of journals hedging forms appear to be differently distributed with the highest frequency in the Discusion and Conclusion (D\&C) section, followed by the Results and the Introduction. It would be interesting enough to see that both journal groups have the same specific hedging forms which might have largely contributed to the difference, except for the Results section. In both RFL and ELT, for example, modal auxiliary verbs have the highest frequency in the Introduction and D\&C while modal lexical items and approximators appear to occur most often in RFL Results and ELT Results respectively. One more noticeable thing is that almost every specific hedging form is found to appear more often in the D\&C than itself in the Introduction and the Results. More importantly, one specific hedging form is also employed with a more varied set of lexical items. The downtoners in RFL, for instance, possesses seven variations in the $\mathrm{D \& C}$ (at least, to some extent, in some respect, part of the reason, roughly, sometimes, and somewhat), but only one variation in the Introduction (partly) and three in the results (essentially, somehow, at least). The situation turns out to be somehow the same in ELT with, for example, nine variations of modal lexical items (appear, assume, believe, imply, indicate, seem, suggestion, suggest, and tend) in the $\mathrm{D} \& \mathrm{C}$, but only four in both the Introduction (feel, indicate, suggest, and tend) and the Results (indicate, suggest, tend, and speculate). 
Up to this point, it would be essential to determine whether the distribution ranks of hedging forms in the RFL Introduction, Results, and D\&C have close relations with those of hedging forms in the three ELT sections respectively. Once again, the Spearman Rank-order Correlation test is applied one time for each section, that is, the ranks of forms in the RFL Introduction are supposed to go with those in the ELT Introduction, and the procedure would be similar to the other two sections.

The computed $\mathrm{r}_{\mathrm{s}}$ positive values are 0.90 for the Introduction, 0.95 for the Results, and 0.93 for the D\&C. According to statistics principles of decision making for Spearman test, the values suggest that there is a very high positive correlation between the two rankings in all three sections, that is, there could be an argument that the use of different hedging forms across three rhetorical sections tends to be similar in two groups of journals.

\section{Discussion and conclusion}

The results analyzed in the previous part have provided evidence for the answers to the two research questions of this study. For research question 1 - What hedging forms and functions are most frequently used in RFL and ELT? - four hedging forms including Approximators, Modal auxiliary verbs, Modal lexical verbs, and Modal lexical items (nouns, adverbs, and adjectives) are found to occur most often in two journal groups. It seems that such forms as Content disjuncts, Reference to study methods/conditions, and Rhetorical questions are not much preferred by both groups of writers. In the case of Hypothetical conditions, this hedging appears to occur mainly in the Introduction section where the writer recognizes the need to convince the reader that work remains to be done in their area of inquiry, thus the need to "establish a niche" (Salager-Meyer, 1997), that is, to suggest that the niche they wish to establish does indeed exist. In terms of hedging functions, it could be assumed that both groups of writers tend to use hedges of the purpose of "hedging" the precision and certainty of knowledge and proposition truth.

The fact that very few rhetorical questions are used as a hedging strategy seems to reflect what Swales \& Feak (1994) suggest an academic writer should follow to maintain a formal academic writing style - an indirect question rather than a direct question (p. 72). Of course, Swales \& Feak also point out that "in some cases, direct questions may be possible" (p. 73). As Hyland (1996, p. 449) states, by using rhetorical questions, the writer expects to draw the reader's attention to a deductive process in which the audience is rhetorically treated as capable of "making the same logical inferences". Also, this kind of hedging may somehow help direct the reader to the core content of the claim or argument which has just been made or is going to be made by the writer. Swales and Feak (1994), however, still stress that "Keep in mind, however, that you should limit your use of these in academic writing" (p. 74).

For research question 2 - How are hedging forms and functions distributed in the Introduction, Results, Discussions and Conclusions sections in RFL and ELT? - the results show that more hedging forms are employed in the Discussions and Conclusions than in the other two sections of both groups of journal articles. This conclusion can also be applied to hedging functions.

In general, based on the data analyzed, it could be concluded that RFL and ELT research articles writers tend to have the same preference for the use of different hedging forms for different equivalent purposes and functions. The best possible explanation could be that the writers all work in the same 
research discipline - linguistics, and therefore they might share "a common sense" of the hedging feature in academic discourse.

Here, it should be made clear that the present study does not aim to compare and contrast the uses of specific hedging items like "can, may, often, usually". What it attempts to do is to make an investigation into the use of hedging devices at a "macro" level. It would be rather "strained" and "forced" to compare such specific items because, presumably, the writers themselves may not assure that they will use a very definite set of specific items. Such an investigation may not reflect a whole picture of the discourse genre studied.

Strauss (2004) discussing cultural standing of expressing opinions considers hedges as an indicator, in connection to other indicators, of cultural standing which is defined as "the location of a view on a continuum that ranges from highly controversial to completely taken for granted in the relevant opinion community" (p. 161). By using hedges, the speaker sees the view as debatable rather than controversial. Thus, the use of hedging devices by RFL and ELT writers in the study partially allows them to set their own professional stance in an academic world.

Hyland (1996) admits that "while hedging is found to be important in a variety of domains, the circumstances recognized as appropriate for its use and the functions it is seen to fulfill often differ markedly" (p. 452). That means some devices may seem to be obviously hedges, but it may actually be not in the view of the writer. Thus, it appears sometimes to be not easy for an analyst, in some certain cases, to decide to what category a hedging device might belong because hedging devices are "polypragmatic" and may often convey a range of different meanings at the same time.

Moreover, it is not known whether the similarities found in this study could be still correct when more articles are chosen for analysis and could be applied to other areas of applied linguistics. All these arguments, in brief, suggest that the limit of this study serve as a call for further extensive research.

\section{References}

Brown, P., \& Levinson, S. C. (1987). Politeness: Some universals in language usage. Cambridge: Cambridge University Press.

Mojica, L. (2005). Filipino Authors' way of showing Detachment/commitment in their English Academic papers. In D. T. Dayag \& J. S. Quakenbush (Eds.), Linguistics and language education in the Philippines and beyond: a festschrift in honor of Ma. Lourdres \& Bautista. (pp. 511-525). Manila, Philippines: DLSU Press for the Linguistic society of the Philippines.

Hickey, D. J. (1993). Developing a written voice. London: Mayfield Publishing Company.

Hua, Yang. (2006). A Comparative Study of Scientific Hedging by Chinese Writers and English Writers. Sino-US English Teaching, 3(3), 58 - 62.

Hyland, K. (1996). Writing Without Conviction? Hedging in Science Research Articles. Applied Linguistics, 17, 433 - 454.

Koutsantoni, D. (2005). Greek cultural characteristics and Academic writing. Journal of Modern Greek Studies, 23, 97-138

Salager-Meyer, F. (1997). I think that perhaps you should: A study of hedges in written scientific discourse. Functional approaches to written text: classroom applications, ed. by Tom Miller, 105-108. Washington, D.C: English Language ProgramsUnited States Information Agency.

Strauss, C. (2004). Cultural standing in expression of opinion. Language in Society, 33, 161-194.

Swales, J. M., \& Feak, C. B. (1994). Academic writing for graduate students: Course for non-native speakers of English. Ann Arbor, MI: The University of Michigan Press.

Varttala, T. (1999). Remarks on the Communicative Functions of Hedging in Popular Scientific and Specialist Research Articles on Medicine. English for Specific Purposes, 18(2), 177-200.

Vassileva, I. (2001). Commitment and detachment in English and Bulgarian academic writing. English for Specific Purposes, 20, 83-102. 


\title{
NGHIÊN CƯUU VIỆC SỬ DỤNG CÔNG CỤ RÀO ĐÓN TRONG DIỄN NGÔN HỌC THUẠTT THUỘC LĨNH VỰC NGÔN NGŨ HỌC ƯNNG DỤNG: TRƯỜNG HỘP CÁC BÀI NGHIÊN CƯU TRONG TẠP CHÍ READING INA FOREIGN LANGUAGE VÀ ENGLISH LANGUAGE TEACHING
}

\author{
Nguyễn Tuấn Anh \\ Khoa Su phạm tiếng Anh, Trường Đại học Ngoại ngũ, ĐHQGHN, \\ Phạm Văn Đồng, Cầu Giáy, Hà Nội, Việt Nam
}

Tóm tắt: Trong viết học thuật, việc rào đón giúp người viết có thể giảm tính áp đặt trong các kết luận hay nhận định được đưa ra (Hyland, 1996). Mặc dù đã có nhiều nghiên cứu về ngôn ngữ rào đón được sử dụng trong các bài học thuật, vẫn chưa có nhiều nghiên cứu về sự giống nhau và khác nhau giữa các tạp chí trong cùng một lĩnh vực liên quan đến việc sử dụng các công cụ rào đón. Bằng cách sử dụng phương pháp phân tích ngôn liệu, nghiên cứu này so sánh đối chiếu việc rào đón trong hai tạp chí ngôn ngữ học Reading in a Foreign Language (RFL) và English Language Teaching (ELT) để tìm ra những dạng thức và chức năng nào của công cụ rào đón được sử dụng thường xuyên nhất trong RFL và ELT, cũng như tìm hiểu sự phân bổ của các dạng thức và chức năng trong các phần khác nhau của một bài nghiên cứu. Dựa trên dữ liệu được phân tích, kết quả cho thấy các tác giả thuộc hai tạp chí này có xu hướng lựa chọn chung đối với những dạng thức rào đón, phù hợp với mục đích và chức năng của từng nhóm dạng thức. Chúng tôi tin rằng xu hướng chung này sẽ có giá trị đối với những ai đang trong quá trình phát triển kỹ năng viết học thuật trong lĩnh vực ngôn ngữ học.

Tù khóa: rào đón, ngôn ngữ rào đón, các phần trong bài nghiên cứu học thuật, viết học thuật 